(C) 2020 Walter de Gruyter $\mathrm{GmbH}$, Berlin/Boston. Access to this work was provided by the University of Maryland, Baltimore County (UMBC) ScholarWorks@UMBC digital repository on the Maryland Shared Open Access (MD-SOAR) platform.

Please provide feedback

Please support the ScholarWorks@UMBC repository by emailing scholarworks-group@umbc.edu and telling us what having access to this work means to you and why it's important to you. Thank you. 


\title{
Ibrahim Er* \\ The voiceless in The Voice: A multimodal critical discourse analysis
}

https://doi.org/10.1515/text-2020-2071

\begin{abstract}
This article highlights the importance of multimodality in the study of discourse with a discussion of a segment from the Turkish adaptation of the global television format, The Voice. In the segment under discussion, a contestant is disqualified from the show by the host for her allegedly disrespectful style of speech towards the coaches. Departing from traditional (sociolinguistic) critical discourse analysis, the article seeks to unveil the deep power discourse hidden in the multimodal landscape of the show by extending the scope of discourse analysis to include both linguistic and non-linguistic modes of communication and representation such as the camerawork, and mise-en-scene. The findings shed light on the inherently asymmetrical nature of the show and how the contestant's highly non-standard language and manners are demonized (multimodally) while the coaches and the host find a relatively less judgmental environment as the "authority" in the show.
\end{abstract}

Keywords: reality TV, The Voice, multimodal critical discourse analysis, power discourse, style of speech, authority

\section{Introduction}

On November 18, 2012, the fans of the popular reality TV show The Voice of Turkey witnessed an extraordinary incident during the blind auditions of its second season. A female contestant in her early 20s came onto the stage and performed a song well enough to get two of the coaches to turn their chairs. However, before she could select the team she wanted to join, she was disqualified from the show for allegedly being disrespectful to the coaches. Her easy manners and intimate language, particularly her use of sen (the informal you pronoun in Turkish), during her conversation with the coaches gradually developed into a crisis of interpersonal communication ethics. Considering it as a sign of "disrespect," the host took the

*Corresponding author: Ibrahim Er, Language, Literacy, and Culture Doctoral Program, University of Maryland, Baltimore County, 1000 Hilltop Circle, Baltimore, MD, 21250, USA,

E-mail: ibrahimer@umbc.edu 
liberty of sending her off the stage after giving her a moral lesson about the prevailing social norms.

The premise of this article is to show that the underlying cause of this incident is the contestant's transgression of the existing power structures between the media and non-media worlds, rather than her violation of interpersonal communication ethics. Her atypical style of communication harasses and disturbs the host and the coaches because it bridges the discursive gap between the (imagined) world of celebrities and that of ordinary people (Couldry 2001), on which the notion of stardom is predicated. On this premise, the article intends to answer the following research question: what could happen if one attempts to undo the media/non-media boundary and debunk the media's power by equating the two worlds and their inhabitants - celebrities and ordinary people? Speaking to larger dynamics and complexities of asymmetrical power relations in societies, this research question constitutes the main thrust of the article and underlies its conceptual framework.

In seeking an answer to this question and shedding light on the complexities of the hierarchical relationship between the said two worlds, the article presents a multimodal critical discourse analysis (MCDA) of the format The Voice and the incident in The Voice of Turkey in particular. Extending the scope of discourse analysis to include both linguistic and non-linguistic modes of communication, which I explain further in the methodology section, MCDA offers the possibility to examine various visual and acoustic modes of representation used in television programs, such as the camerawork and mise-en-scene, along with the dialog.

With regard to the organizational structure of the article, I first give a background of the format The Voice and elaborate the hierarchical structure that it reinforces between the ordinary and celebrity bodies. Next, I provide an overview of previous studies concerning television formats and then, in the methodology section, introduce the concept of multimodality and discuss how MCDA can empower the study of televisual texts. This is followed by a hermeneutic semiotic analysis of The Voice's visual design (staging, props, colors, and lighting), which I argue potentially contributes to the construction and perpetuation of the boundaries and hierarchies of the media/non-media consumption landscape. This preliminary breakdown of the show's visual composition, which can also be applied to other programs of the same nature, becomes essential to understand the ways in which The Voice and other similar shows create an antithesis - a dream world - to the "ordinary world" and represent a simulacrum of the media world and its power. Next, I examine the particular incident at stake. The in-depth analysis of this peculiar incident reveals further insights into the media/non-media hierarchical boundary and provides a more robust, empirical foundation for 
understanding how the power dynamics shapes relationships between the two worlds. Finally, while the discussion section interprets the key findings, the conclusion section summarizes the study.

\section{The Voice: A format at the intersection of the media and non-media worlds}

There is ... a boundary, regularly legitimated and symbolically effective, between 'media world' and 'ordinary (that is, non-media) world', a boundary which is 'absolute' in Durkheim's sense, so that any crossing of it, or even approach to it, is automatically significant. (Nick Couldry 2001: 171)

It is not a coincidence or an oversight on Couldry's part that he makes this structural categorization of the media/consumer landscape at a time of pervasive postmodern uncertainty. Given especially the growing popularity of reality television programs since the early 1990s, featuring mostly "ordinary” (non-media) people, and the rise of alternative media platforms like YouTube, it is now harder than ever before to tell who belongs to what world, or who is a celebrity, and who is "ordinary." Couldry (2001) problematizes the blurring of this symbolic boundary between the media and non-media worlds and the unprecedented movement of people across the consumption landscape. According to him, this fading boundary is exactly where the media's power resides - a symbolic power that gives media institutions and the realm of celebrity culture a superior position vis-à-vis the nonmedia world. The occasional movement of people across this hierarchical structure be it a celebrity spotted out shopping in an ordinary store (see Littler 2004) or an ordinary person becoming a celebrity for a few months - serves only to reinscribe and reinforce the now-cloaked media/ordinary boundary and legitimize the socially constructed symbolic power of the media.

The Voice, a reality television singing competition format that was created by the Dutch media tycoon John de Mol in the Netherlands in 2010 and has generated over a hundred adaptations around the globe over the years, is a quintessential example of this postmodern mobility at stake. Played exactly in the media/ordinary border zone, the show provides thousands of non-media people each year a chance to step into the media world and be part of its vibrant celebrity culture. Following an untelevised producers' audition, the qualified contestants begin their journey in the show with a televised blind audition in which they perform an excerpt of a song on a stage where four celebrity coaches sit on chairs facing towards the audience. If the coaches like a performance, they press a button located in front of them to turn their chair, indicating their interest to coach the 
contestant for the rest of the season, and thus open the doors of the media world to the "ordinary." The contestant either joins the team of the only coach who turns around or selects one of the coaches if there are more than one. After all the coaches have a set number of contestants in their teams, the show continues with various other stages in which the contestants compete against each other to eventually win the show and get the big prize.

Despite the appeal of the open-to-all concept of the show and its promise to transform lives for the better, it is evident that only a small fraction of applicants make their way to the stage and even a smaller number gain fame in it - though fleeting it often is. Sooner or later, the glamorous scene of the show becomes a site of disappointment and failure for almost all of them, even including the winners whose fame often fades away as suddenly as it appears. Why do then thousands knowingly participate in an adventure that is laden with many failures and few ephemeral successes? Is it because they have got nothing to lose, or do they lose something by straddling the boundary between the non-media and media worlds? An even more critical question is: who benefits from these disappointments and failures? The incident that happened in the Turkish version of the format in 2012 offers a unique opportunity to explore these questions.

\section{Literature review}

\subsection{The study of television formats}

The worldwide popularity of television formats since the 1990s has drawn the academic attention towards the social, political, economic and cultural dimensions of media globalization (see Aveyard et al. 2016; Bielby \& Harrington 2008; Chalaby 2016; Havens 2006; Miller \& Kraidy 2016; Moran 2009; Oren and Shahaf 2012; Parks \& Kumar 2003). The steadily growing body of literature has diversified over the years, offering a wide range of approaches and perspectives. These include (as categorized by Aveyard et al. 2016): cultural analyses (e. g., Adriaens \& Biltereyst 2012; Unur 2015), cross-cultural comparisons (e. g., van Keulen \& Krijnen 2014; Larkey et al. 2016), studies on the political economy of formats (e. g., Ganguly 2012; Yesil 2015), historical inquiries (e. g., Dechert 2016; Ferrari 2012), and audience studies (e. g., Holt and Samson 2014), to name just a few.

Among these approaches and perspectives, the textual analysis of television formats takes an essential role because of the cultural baggage various formats are laden with as they work their way through different political landscapes and media cultures. Despite the apparent thematic and stylistic similarities between different 
versions of the same formats, their actualization in each national context holds and reflects a significant amount of information regarding the deep structures of the dominant culture in which they are replanted (Gray and Lotz 2019: 36). Analyzing their culturally reshaped textual design and content bears a huge potential to reveal traces of prevailing social discourses of power asymmetries and ideological struggles.

\subsection{The multimodal nature of television narratives}

The importance of multimodality for the study of television programs and films has been evidenced by a growing number of case studies in the last decade. In their study of a 6-min interview between a climate scientist and a climate denialist on Fox News, for instance, O'Halloran et al. (2013: 665) illustrate how various semiotic resources such as the different uses of camera angles, mise-en-scene, clothes and body languages account for the appearance of the climate denialist as "the dominant and convincing interviewee." Similarly, Eriksson (2016: 306) conducts a multimodal analysis of a Swedish docu-soap entitled A Mighty Journey with Morgan and Ola-Conny. His findings reveal how the musical score, the sequencing of the scenes, and the camerawork play a role in representing the participants of this show as "outdated, uncultured, un-dynamic, and inflexible." In another study that focuses on another Swedish docu-soap entitled Boda Camping, Eriksson and Machin (2017: 319) further examine the impact of the musical score, including melodies, rhythm, articulation and sound arrangements, on the de-legitimation of "working class culture and lifestyle" in entertainment television programs. Last but not least, Dash \& Patnaik (2016) use multimodal discourse analysis to scrutinize three Indian TV commercials and discuss how these commercials create a "cultural third place" between global and local discourses through music, setting, and the narrative structures.

The promising findings of these research studies and several others that I could not include here due to space limitations create a pressing need to increase the number of similar multimodal approaches in television studies to better understand the complex nature of the meaning-making process in television programs.

\section{Data and methodology}

The TV show, The Voice of Turkey, was broadcast in Turkey, where at least 98 percent of the population has access to television, and TV viewership is still "the 
dominant source of information and entertainment” (Yesil 2016: 5). Moreover, the producer/host of the show is one of the most well-known public figures in the country. As a result, the particular incident under examination hit the headlines the following day and was discussed widely in various magazine programs, ${ }^{1}$ which makes it an interesting case worthy of scholarly attention.

The video clip has been accessed from the publicly available website of the broadcaster Star TV. ${ }^{2}$ The transcriptions and the translations from Turkish to English have been carried out by the author. The transcription conventions include: brackets for overlapping speech, and <imitating > signs to mark the speaking mode. Additionally, the bold typeface signifies the informal you pronoun and informal phrases such as jaa, a common informal filler word in Turkish, and verbs that sound informal or include an informal 'null subject' in it, in contrast to the italicized words for the formal you pronoun.

My analytical framework is multimodal critical discourse analysis (MCDA) which extends the domain of traditional (sociolinguistic) study of discourse to include other visual, sonic, musical, and material modes and semiotic resources of meaning-making along with the verbal language (Bateman and Schmidt 2012; Bateman et al. 2017; Kress 2003; Ledin and Machin 2017; Machin and Mayr 2012; Machin 2013). Its inclusion of these various modalities does not necessarily posit an exclusivist view of communication sidelining language, but rather a reformative one reconceptualizing what we mean by language (Jewitt 2014). It provides researchers with a critical and more comprehensive lens to examine communicative situations closely and analyze their complex organizational (textual, spatial, and temporal) design and construction to unravel meanings and discourses hidden in the cracks of their multimodal borders.

In the analysis of the format The Voice and the incident in question, in particular, MCDA helps illustrate how inequalities in power between the media and non-media worlds are shaped and perpetuated through various modes. It allows the researcher to question, for instance, the design of the stage and the turning chairs, the role of the audience during conversations, the use of camera angles and movements and shot sequences to convey meanings, and above all, how such design elements provide a "frame" for the communications between the celebrities and the contestant.

\footnotetext{
1 Many national newspapers such as Hürriyet, Star, and Haber7 highlighted how the contestant's unconventional manners annoyed the host, leading him to disqualify her from the show with the support of the coaches and audience.

2 See https://www.startv.com.tr/video/arsiv/program/o-ses-turkiye/o-ses-turkiyede-gerginanlar-acun-ilicali-ve-nur-cennetin-soz-duellosu- for the original clip. Also, see https://www. youtube.com/watch?v=7aYtJU5BEu0 for the subtitled version of the analyzed segment.
} 


\section{Analysis}

In what follows, I first analyze the setting (mise-en-scene) of the show to illustrate how it creates a visual boundary between the media and non-media worlds. In the second part, I focus on the incident in The Voice of Turkey and conduct a momentto-moment multimodal analysis of the interaction between the contestant, the coaches, and the host, and explore how the power dynamics is played out among them.

\subsection{Setting (mise-en-scene)}

Setting (mise-en-scene) in televisual productions is an essential part of meaningmaking because it can reflect and reinforce social and cultural structures and power relations. The selection and arrangement of design elements and their lighting, sizing, and spacing can define parameters of relationships between characters, establish the mood of a story, and manage expectations. These stylistic elements become especially important and evident in programs such as The Voice where ordinary and celebrity bodies are juxtaposed and situated in an asymmetrical power relation. The inherently privileged status of celebrities as the "experts" and "hosts" in these shows is often reflected in the way they dress and are presented, how the stage is arranged and lighted, and in various other visual elements (colors, props) that make up the scene.

The design of these material resources also become functional in turning discourses into objects and ideas into reality or creating illusive representations of reality. As Fiske (2011: 262) observes:

Images are neither the bearers of ideology, nor the representations of the real, but what Baudrillard calls 'the hyperreal:' the television image, the advertisement, the pop song become more 'real' than 'reality,' their sensuous imperative is so strong that they are our experience, they are our pleasure.

In the case of The Voice, we observe this function of the visual design in the promotion and realization of the idea of a celebrity "dream world" that the contestants want to enter and be part of. The colorful design of the studio corresponds to and signifies what the show promises and brings the contestants - a transformation into celebrity stardom - and the sumptuous stage becomes the site where this assumed transformation happens. Moreover, this reified image of the "dream world" also represents the realm where celebrities dwell. Their encounters with "ordinary" bodies in this hyperreal realm provide them with a chance to prove that their famous identities are real and tangible, and so is their glamorous 
celebrity culture - which are otherwise vulnerable to become an illusion or even a simulacrum, in Jean Baudrillard's (2011) terms, in which the link between a representation and the real is lost. It is through such tangible experiences in which celebrities meet "ordinary" people that the missing link between the two worlds is revived, and the illusionary identities of the celebrities, as well as their privileged positions, are actualized and legitimized. Within this context, the disappearance of the boundary between the two worlds by no means ensures an egalitarian ground for the contestants.

It is, therefore, crucial to start with a brief discussion of the asymmetrical setting of the show, including the staging, the concept of the turning chair, colors, and lighting, all of which serve as a frame for the incident that I discuss later in the article.

One of the visual ways the concept of the dream world and the hierarchies it amplifies manifest themselves is the staging in the show. Stage in the world of music is known as a platform or a raised floor on which an artist delivers her/his performance. In the case of The Voice, it is also supposedly the raised platform in the very center of the studio where the contestants perform their songs. However, what is often not realized in this particular show is that the so-called "singing stage" in fact constitutes only a background to the coaches (see Figure 1). In other words, I call the foreground where the coaches sit the "actual stage." Even when a contestant is singing in the background, the lights are always on the coaches in the foreground, and people curiously watch them to see whether they will like the

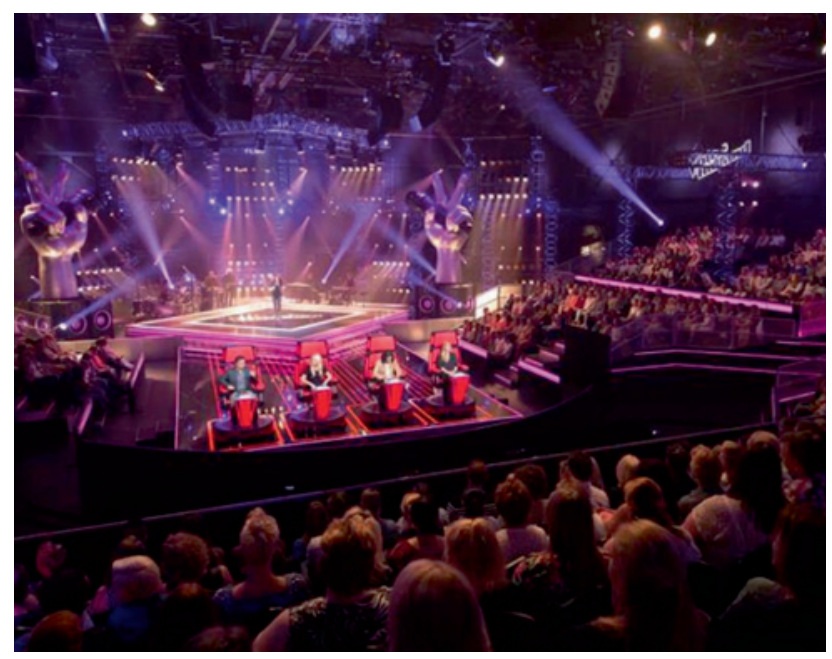

Figure 1: Staging. 
performance and push the button, or not. While this relationship between the two stages is always evident to the audience present in the studio, it is also revealed to the viewers watching the show on their televisions at several points throughout the program by means of establishing and re-establishing shots. The contestant, his/ her performance, and the pseudo-stage all in the background become the object of the main actors sitting in the actual stage in the foreground on their large chairs.

The concept of turning chair and the position of the coaches during the blind auditions also contribute to the same idea of actual stage. To begin with the size and color of the chairs, it is evident that the chairs the coaches sit on are larger than usual chairs, which assumedly symbolizes their authority and stardom as the coaches in the program. Likewise, red is also known, in general, as the color of power in today's social world. We witness the same semiosis in red carpet ceremonies in politics and events like the Academy Awards. More important than these semiotic symbolic representations, though, is the position of the coaches. They start to listen to each performance at the beginning facing away from the contestants. In other words, the contestants start their performances in a disadvantageous position because they first are obliged to prove themselves to the coaches, the authority, in order to be regarded as a real talent. In other words, they need to earn the coaches' attention and approval before they can become a real contestant.

Another stylistic element that plays a role in the construction of the concept of the dream world and the boundary between the two worlds is lighting. As seen in Figure 2 above, a significant majority of lighting on the stage is pointing in random

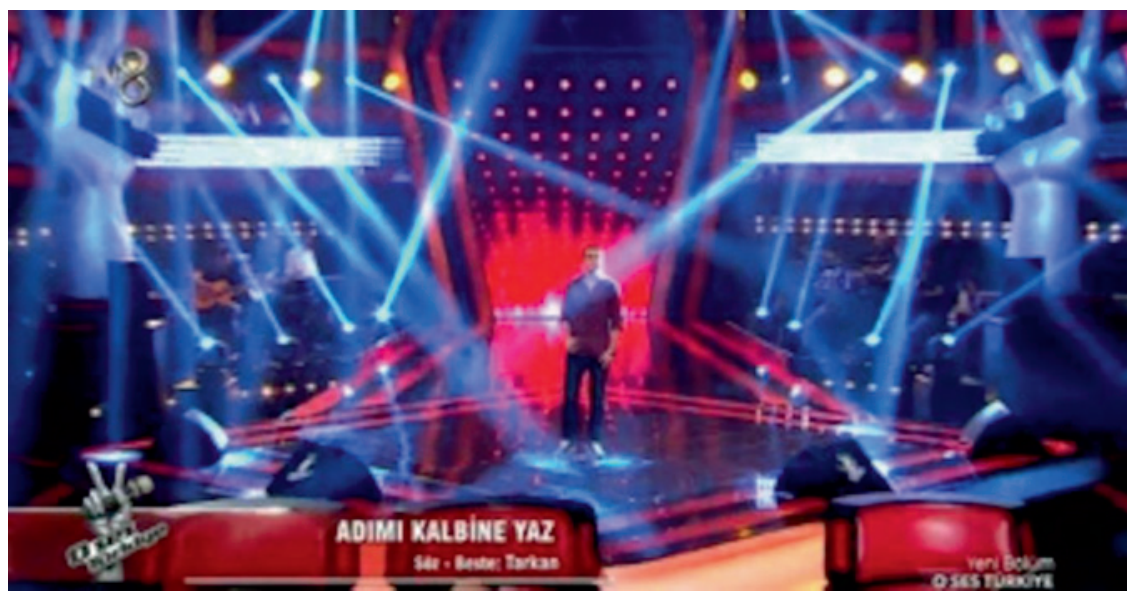

Figure 2: Lighting. 


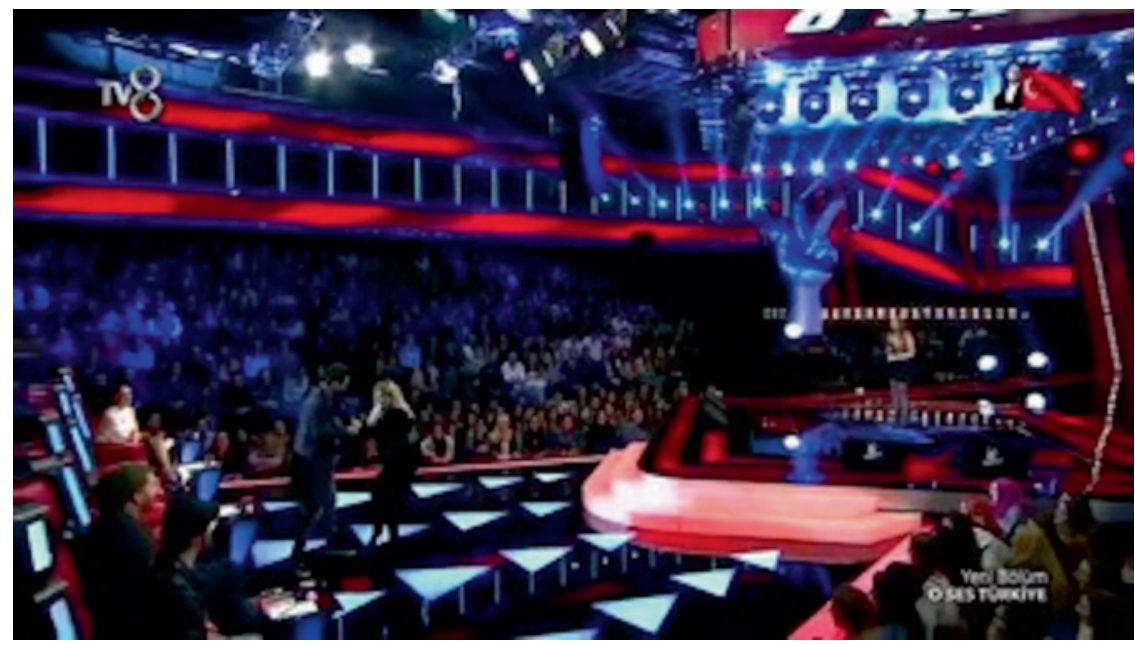

Figure 3: Floor lighting.

directions. In other words, they do not function as a tool to light the contestant. It is this image of a dream world that stands out in the frame, rather than the contestant from the "ordinary" world.

Lighting on the floor (see Figure 3) also signifies essential meanings, especially those with arrow shapes that tie the stage where the coaches sit and the stage where the contestants perform. These lights, literally connecting the two "worlds," are turned on only when and if the coaches, as gatekeepers, push the button in front of their chairs and allow the contestant to pass to the world of the famous. Otherwise, their faces and voices are erased from the memories of the viewers for not being good enough.

It is not counterintuitive to suggest that these main stylistic elements of the show contribute to the construction and perpetuation of the hierarchical boundary between the media and non-media worlds. In other words, they pre-determine or pre-configure the relationship between the two worlds and are thus an active component in constructing and maintaining social power relationships and the hierarchical construction of difference. However, the actual discursive work takes place and comes into prominence in contexts where and when the protagonists interact with each other, and their interests, values, and expectations clash. The incident that happened in the Turkish version of The Voice in 2012 is the epitome of such a situation, to which I turn next. 


\subsection{The incident}

Nur Cennet Uçar, the disqualified contestant, is a musician coming from a midsized Anatolian city, Mersin. Having years of experience on stage despite her young age, she immediately stands out as a notably overconfident person compared to many other contestants during the introductions. As a matter of fact, she manages to start a rather friendly conversation with the coaches and the host at the beginning. However, the conversation soon turns into a crisis, which is where I begin my analysis.

The agents in this segment are listed below with their abbreviations in parentheses, which is followed by the transcript of the incident.

$\begin{array}{ll}\text { Coach A - Murat Boz } & \text { (C-A) } \\ \text { Coach B - Hülya Avşar } & \text { (C-B) } \\ \text { Coach C - Mustafa Sandal } & \text { (C-C) } \\ \text { Coach D - Hadise } & \text { (C-D) } \\ \text { The contestant - Nur Cennet Uçar } & \text { (Cont.) } \\ \text { The host - Acun Ilıcalı } & \text { (Host) } \\ \text { The aunt - The contestant's aunt } & \text { (Aunt) } \\ \text { Audience } & \text { (Aud.) }\end{array}$

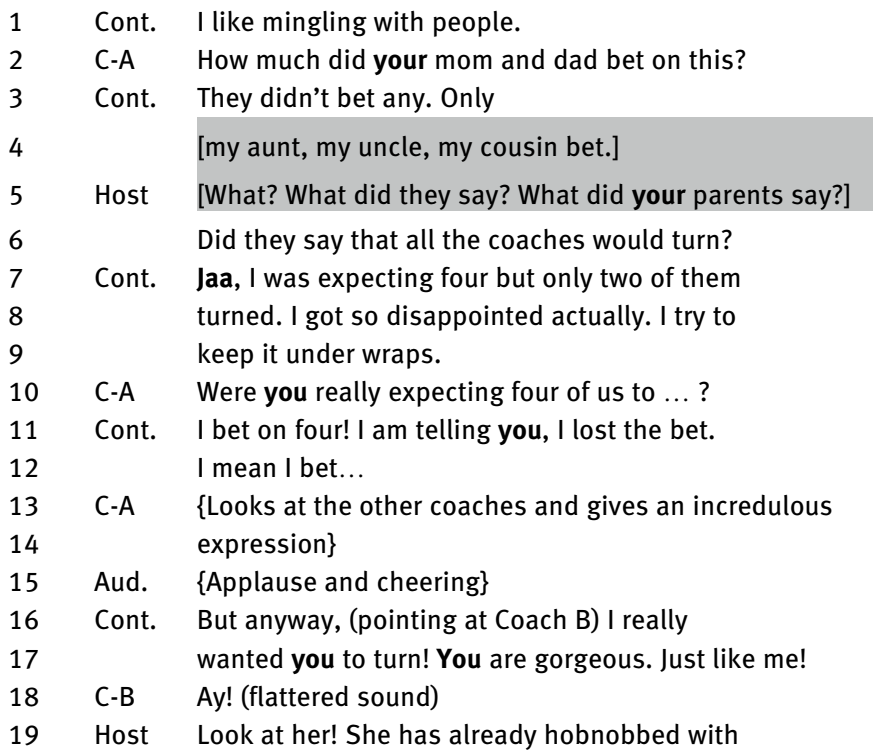


(continued)

20 all of you \{said in an ironic manner\}

21 C-A Yes, indeed.

22 Cont. No, I mean they are eventually just like us -

23 beautiful.

24 Host Yes, of course \{sounds ironic

25 Aud. \{A small proportion of Audience laughs\}

26 C-A What do you mean by 'us?'

27

C-C $\quad$ speaking ironically\} Whoever marries you is a lucky man!

Cont. $\quad$ looking and pointing at Audience We all are beautiful?

C-A Doubtless.

Cont. Ha? \{looking at Audience\}

C-A Of course.

Host What is your education?

Cont. I dropped out of university. Very nice!

Host You dropped out. Very nice!

Cont. Yes, very nice.

Host The competitors in this program usually address our coaches in the formal 'you' form.

Have you ever watched the program?

Cont. How are you?

Host No, not like canting. Other competitors do it from the bottom of their hearts.

Aud. $\quad$ Applause and cheering start with a few people and expand to other audiences quickly\}

Cont. Wait a minute. \{Applause continues.\}

No. No. Wait a minute. No. No!

Aud. Acun! Acun! Acun! \{calling Host's name in unison\}

Cont. But, no! Let me

[explain. Do not misunderstand]

Host [No, no. let me tell you something. No, no. Look.]

When you address our coaches in the informal 'you,' you don't become intimate with them. Do you understand?

Cont. No, I always respect them. This shouldn't be interpreted like that. Please.

Host Look, I know that. Look now. To a person that you just met, look, I guess nobody could teach you this before, let me tell you, when you are talking to a person that you just met, people usually use the formal 'you' form.

Cont. But it is because I love them so much that I prefer the informal 'you' form. 
(continued)

64 Host Yes, it might be because you love them but saying

65 <imitating>you turned, you didn't $<$ /imitating> and

66 so on. That is...

67 Cont. No, not like that.

68 Host OK.

69 Cont. Please do not interpret it like that.

70 You misunderstood me.

71 Host OK. I can feel that you are pure in heart,

72 but there are some behavioral issues.

73 Cont. I ... No, no.

74 Aud. \{Applause and cheering\}

75 Host Unfortunately.

76 Cont. \{Contestant grins at them

77 Host I guess you are roughly the thousandth contestant

Cont. I can't know that.

Host Well, OK, anyway, when you go out in public, speak more neatly \{explicitly insulting\}

82 Cont. OK, I mean, OK. This is no good.

Why do you do this to me?

84 Host No, look, your style of speech, what is it? Let me explain it to you. It's not all about the informal pronoun. It is your style of speaking in general. <imitating>You turned, you didn't, you did</imitating> If we allowed this today, all of our contestants in the future would start addressing our coaches in this style. What makes them different from you, then? OK, I got it. You didn't like my style of speech.

92 Host Not that I didn't like. It wouldn't get any better anyways. It cannot get any better with my warnings.

94 Cont. No, no.

95 Aud. \{Applause and cheering\}

96 Host On that matter. On that matter, there is nothing

97 that I can do. Got it?

98 Cont. But, I, I don't agree; I don't agree with you.

99 Also, I don't think that I speak wrongly.

100 Host \{Looking at the coaches\} All yours. Whoever

101 wants to add her to his/her team, go ahead.

102 Aud. \{Audiences, coaches, and Contestant laugh\}

103 Cont. \{sounding very informal\}Who turned for me,

104 jaa, by the way?

105 Aud. \{Audience growling and roaring\}

106 Cont. Ha ... OK...

107 C-C <imitating> Who turned for me, jaa? </imitating> 
(continued)

108 C-D I think you are speaking in a very wrong style.

109 There is a big disrespectfulness towards us. Really.

110 Cont. But I didn't mean it.

111 C-D I feel that way, though. As a coach, this is

112 the first time I am feeling this way.

113 Cont. I don't know ... I don't think that I spoke

114 wrongfully, jaa. Did I do something wrong?

115 No, I only asked who turned. I asked who turned.

116 Host No, OK, You...

117 C-D Yes.

118 Host Let's not continue this anymore. Thank you for

119 coming! We send you off with applause.

120 Aud. \{Applause and cheering\}

121 Cont. \{Contestant comes off the stage This is nonsense.

122 Aunt It is OK, my dear. No, no, no, it is OK. It is

123 normal. OK, OK, OK. You will learn over time.

I want to begin my analysis of the incident by partitioning the text into three consecutive parts based on two turning points that change the course of the conversation.

The first part starts from the beginning of the video clip (line 1) and continues until the moment right before the host asks the contestant's education level (line 34). The striking thing in this opening part is the fact that the contestant dominates the conversation substantially by talking for $70 \%$ of the time (see Figure 4) and surprises the coaches and the host with her easy manners and informal style of speech (lines 7, 11, and 17).

Aware of the quirkiness of the situation, the coaches and the host make a few insinuations about the contestant's style of interacting with them and the audience (lines 19, 20, 21, 24, 26, 27, 28, and 29); however, they do not denounce or confront
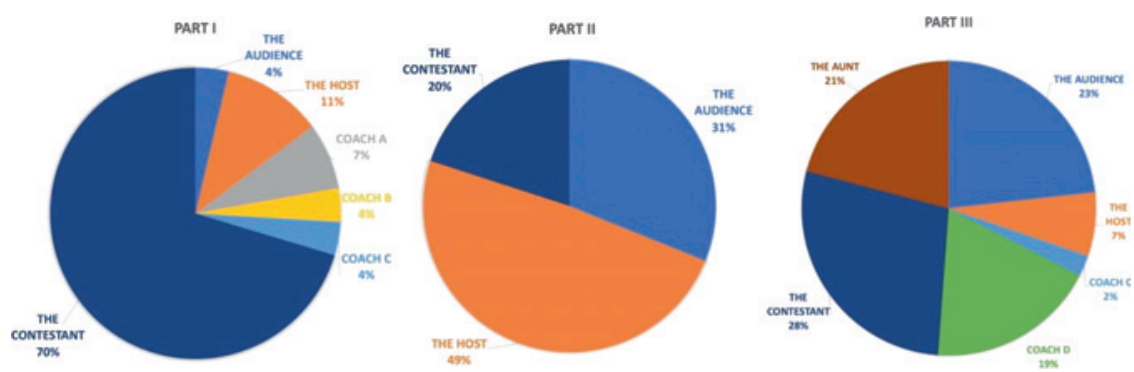

Figure 4: Three parts in the video clip. 
her unusual attitude exclusively yet. Later, the contestant's consistent use of the intimate language and easy manners eventually leads the host to make some assumptions regarding her education level (see further below), and he asks her a critical question, "what is your education?" (line 35). This question shifts the content, the style, and the manner of the conversation drastically from an "intimate" one to a bitterly antagonistic debate between the host and the contestant.

I regard this moment as the turn of a new conversation, and thus of a new segment in the video clip. It is striking but not surprising that, in this second section, the contestant suddenly switches to the formal you pronoun (i. e., siz) and uses it consistently in four different sentences (lines 70, 83, 91, and 98), ${ }^{3}$ while the host seizes this opportunity to predominantly lecture the contestant what he thinks is the "normal" way of speaking, with the support of the audience and the coaches. This time the host dominates the conversation by talking $49 \%$ of the time as opposed to the contestant's 20\% (see Figure 4).

Finally, the third section of the conversation starts when the contestant switches back to her informal language and manner and asks the question, "who turned for me, jaa, by the way?" (lines 103 and 104). Her act immediately signifies for the host, the coaches, as well as the audience that she did not learn her "lesson" from the host's lecture on the society's norms. She can use her intimate language only one more time before she is sent off the stage and disqualified from the contest by the host. In the rest of my analysis, I will refer to these structural changes in the conversation by the partitions I made above, namely, the first, the second, and the third sections respectively.

The first section of the conversation (lines 1-34) opens with the contestant talking about her outgoing personality. Her assertive gestures and body language

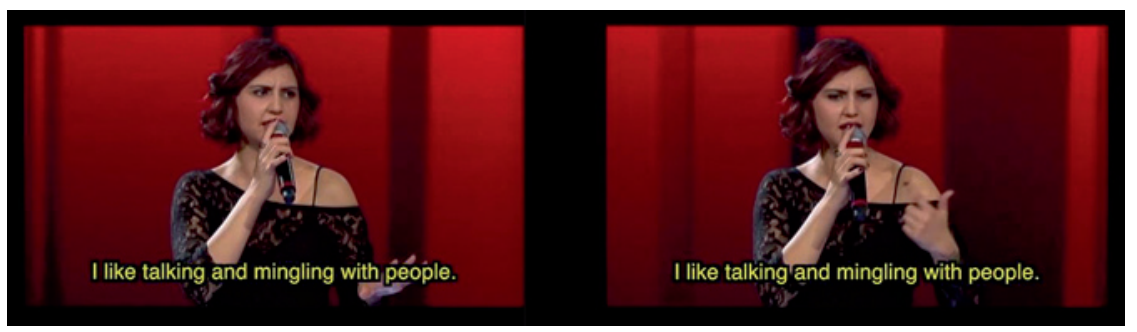

Figure 5: The contestant's assertive gestures.

3 I am excluding the first time she uses the formal you pronoun in line 42 because she uses it in a clearly out of place and disrespectful way (in effect if not in intention.) She is just parroting back a conventionalized use of a formal pronoun that hardly fits interactionally at that point. 
with strong eye contact throughout line 1 stand out as the first indicators of her assurance in her identity and abilities, which are clearly captured and shown by a medium-close-up shot of her (see Figure 5). After Coach A's question about the bet she had with her family, though, the camera switches to a full shot of her body (lines 3 and 4 - see Figure 6), which captures her taking a few steps toward the coach while counting off the betters on her fingers. These body movements and her continuing strong eye contact with the coach once again confirm her assertiveness and can be read as her desire to be in control of the conversation.

As she answers coach A's question in line 4, the host overlaps her speech and asks about her parents' predictions on her performance. Given the contestant's assertiveness up to that point, this overlap can be read as a move by the host to hold the floor, reminding her that he is in control of the conversation. However, what is more important than this speculative interpretation is that the host (line 5), as well as Coach A in line 2, use the informal you pronoun (sen, in Turkish) when addressing the contestant. This linguistic distinction, also known as the T/V distinction corresponding to $\mathrm{tu} /$ vous in French, is enforced in Turkish as well as in many other languages to determine and emphasize the social distance - the degrees of deference and intimacy - between speakers and hearers. While the singular you ( $\mathrm{T}$ - tu, sen) describes familiarity and closeness, the plural you pronoun (V vous, siz) describes formality. Their preference for the informal you pronoun, in this regard, indicates either the intimacy they feel toward the contestant or the lack of

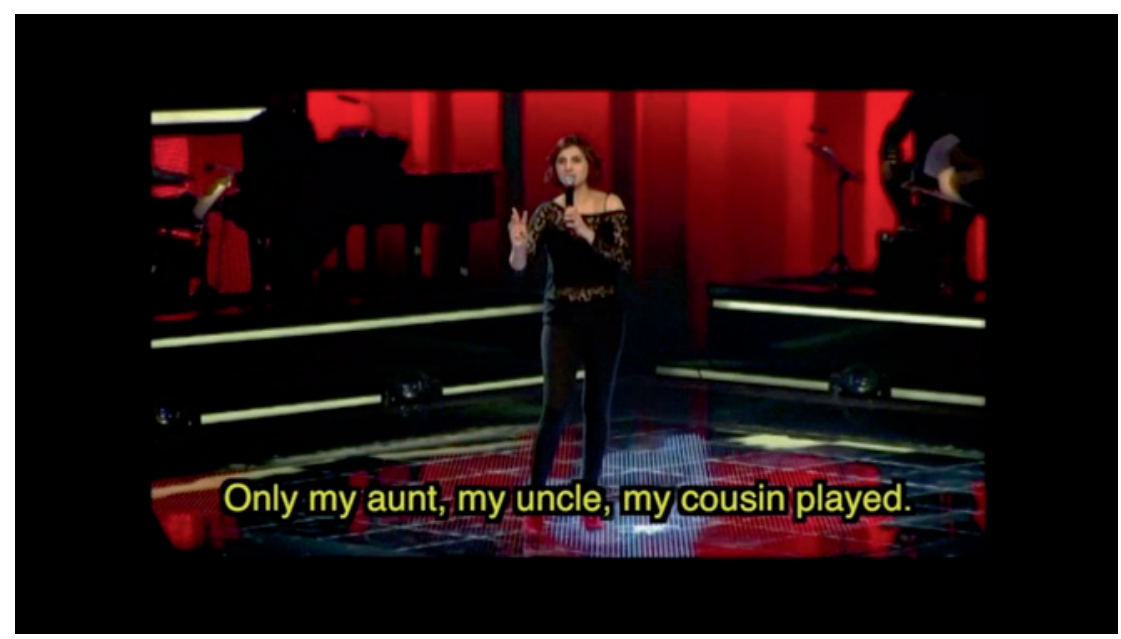

Figure 6: Full-shot. 
interest in showing deference to her because of their superior positions in the show. I will return to a discussion of this point further below.

Responding to the host's question, the contestant continues her open-handed gestures and easy manners in lines 7-9, which are again clearly shown in a medium-close-up shot. More importantly, though, she uses the common informal filler in Turkish, jaa, at the beginning of her sentence. Similar to the host's and coach A's language choices, this informal filler also becomes an indication of either the closeness she feels toward the coaches and the host, or her lack of interest in showing deference to their higher status.

After a follow-up question by Coach $\mathrm{A}$ in line 10, in which he again uses the informal you pronoun, the contestant starts to speak even more loudly and with exaggerated pitch and body movements - her head in a striking forward position of assertion (see Figure 7). Equally important, she uses various informal you pronouns in lines 11 and 17 and points at Coach B with her finger as she says that she expected her to turn (lines 16 and 17 - see Figure 7). Last but not least, after praising Coach $B$ in line 17, saying she is gorgeous, the contestant equates her beauty to Coach $\mathrm{B}$ and sticks her tongue out and performs various facial expressions of a curious sort (see Figure 7). Throughout this whole time, we see a medium-close-up shot fully displaying her unexpected acts, except for two quick intercuts showing Coach $A$ and $B$ around lines 15 and 16 to resolve reference of pointing (presumably). What is striking in these intercuts is that both coaches give incredulous looks and

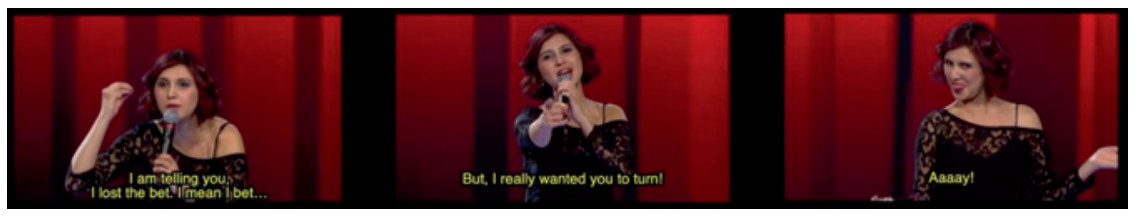

Figure 7: The contestant's exaggerated body movements and facial expressions.

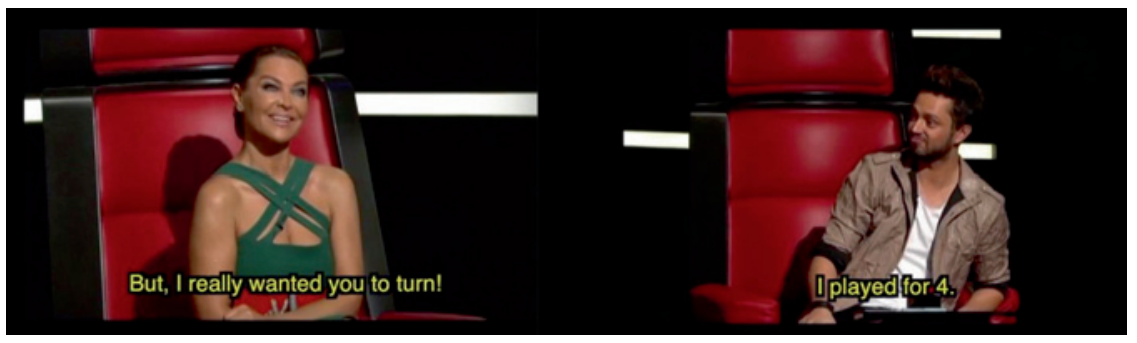

Figure 8: The coaches' incredulous looks. 


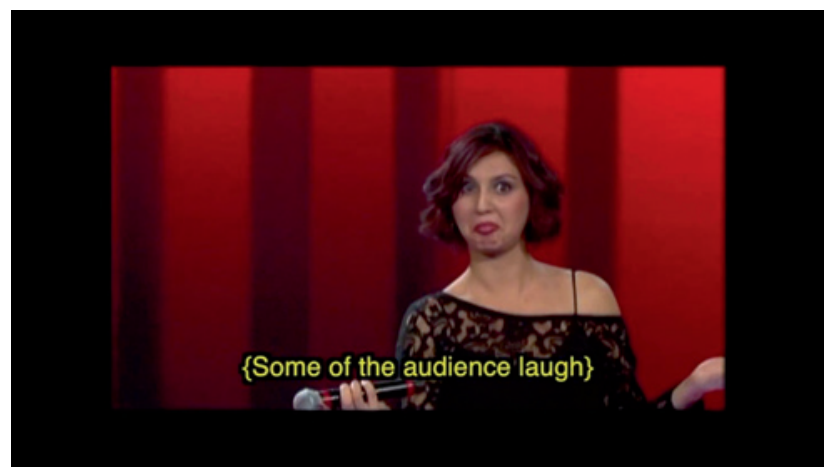

Figure 9: The contestant's facial expression.

Coach A performs a wide arc movement (see Figure 8). These shot sequences signify increasing incredulity among the coaches.

From line 19 to the end of the first part (line 34), we start to see the coaches and the host making a few insinuations about the contestant's style of interaction (lines 19, 20, 21, 24, 26, 27, 28, and 29). In lines 19-21, after the contestant's remarks about Coach $\mathrm{B}$ and herself, the host raises his concern about her informal manners with an ironic rhetorical question, which is followed by an ironic expression by Coach A. In response to these, the contestant attempts to justify her position in lines 22 and 23, in which she extends the equation she made between Coach B and herself to a larger scale between all the coaches and the audience. She states that both the coaches and the audience and herself are all the same - beautiful - and ends her statement with more facial expressions of a curious sort, all of which are again clearly captured in a medium-close-up shot (see Figure 9). However, her justification attempt receives further ironic responses from the host and Coaches $\mathrm{A}$ and $\mathrm{C}$ in lines 24, 26, 27, 28, and 29. While Coach A asks who she means by "us" (pointing

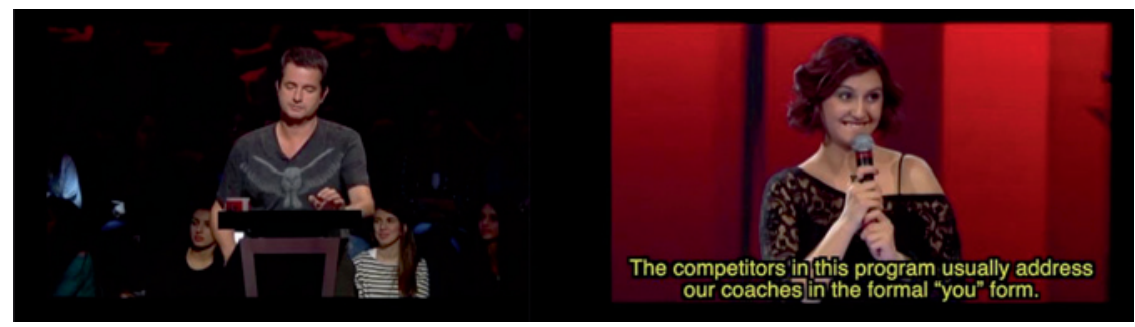

Figure 10: The host and the contestant. 
at the stage where she stands by herself), Coach $\mathrm{C}$ shows his displeasure of her manners by stating how lucky her future husband is (in an ironic way).

Another interesting aspect of the text through which the increasing quirkiness manifests itself at this point is the audience participation. In response to the contestant's attempt to equate the "beauty" of the audience with that of the coaches, only a small number of the audience applauds. More importantly, when she persists on her idea in lines 30, 31, and 33, she receives no applause. Given the fact that, in television production studios, directors almost always guide audience responses by determining when they should applaud and cheer, and when they should cease such activities and stay silent, this gradual decrease in audience responses to the contestant also deserves attention.

The second section of the conversation starts when the host asks the contestant about her education level (line 35). A clear indication of his assumption that only an "uneducated" person can dare to rule out socially accepted rules and norms, this question signals his intention to set out and discuss some typically received "norms" of the Turkish culture, especially in terms of how one should speak in public. The contestant, presumably aware of the imminent crisis, tells that she dropped out of university but adds an out of place phrase, "very nice," at the end of her sentence, which the host mirrors back and then the contestant repeats (lines 36, 37, and 38). This verbal sign of interactional trouble and evaluation is also supported visually by a medium-close-up of the host thinking with his head

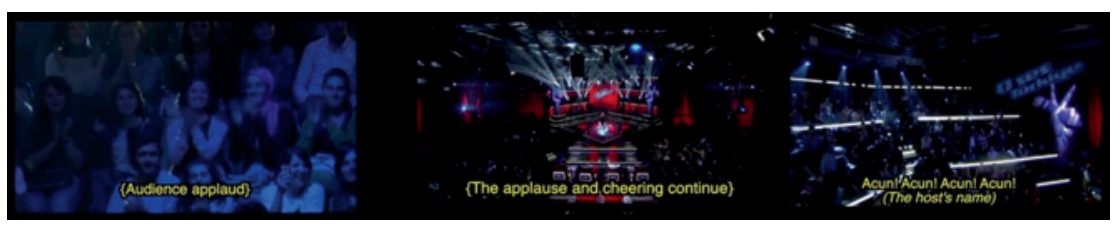

Figure 11: The audience.

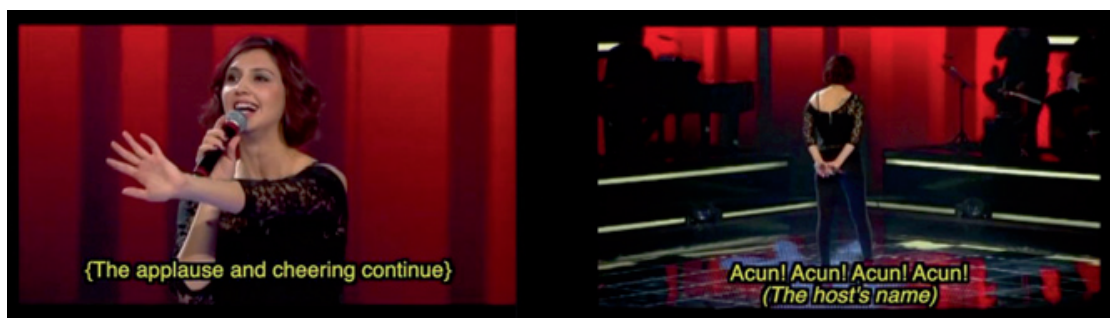

Figure 12: The contestant's failed relationship with the audience. 
down and a consecutive medium-close-up of the contestant biting her lower lip (see Figure 10). From this point on, the host starts using a more direct language in his warnings about the contestant's style of interaction.

One of the strategies the host uses to justify his arguments in this section is to ask the contestant to compare herself with the other contestants in the show who address the coaches in the formal you pronoun (lines 39-41, 77-78, and 88-90). As in his previous question about her education level, this comparison also assumes and argues that the acts of the majority, i. e., the "educated," are the normalcy and thus should be taken for granted. Alerted by the host's direct warning, the contestant immediately switches to the formal you pronoun and asks the coaches how they are in a formal way (line 42). However, this question sounds clearly out of place and certainly disrespectful (in effect, if not in intention) and immediately meets the host's objection (lines 43-44).

Next, applause and cheering follow (lines 45-46). What is noteworthy here is that the applause and cheering start with only a few people and then suddenly spread to the whole crowd within seconds. This is another crucial cue for assuming that someone, i. e., the director, tells the audience to applaud and support the host, the powerful. Moreover, it is also highly likely that the audience starts shouting out the host's name in line 49 (following the contestant's rejection to their support for the host) because they are told (or guided) to do so by the director.

The camerawork during these moments is also of great importance as it shows a sequence of shots displaying the audience support for the host. First, in lines 4546, it shows a zoomed shot of about a dozen audience members applauding the host's comments, which is then followed by an extremely long shot displaying the whole studio and then a left pan of the audience section in line 49 (see Figure 11). Especially the extremely long shot of the whole studio is noteworthy in that it shows the contestant as small on the stage or at a distance and serves a role of distancing identification, thus reducing subjective alignment with her. The two momentary intercuts to the contestant during the moments when she tries to stop the audience cheering and then when she turns her back to the audience are also significant in revealing her failed relationship with the audience (see Figure 12).

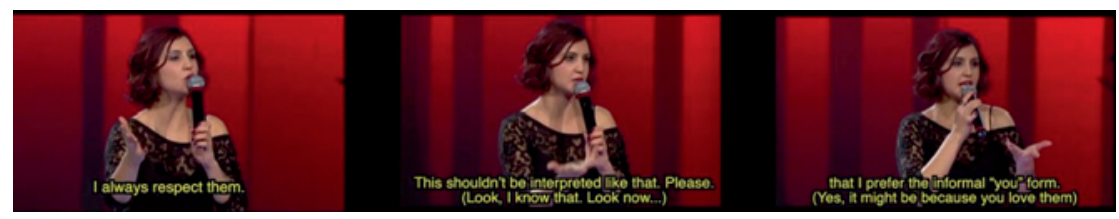

Figure 13: The contestant's strong hand gestures and facial expressions. 


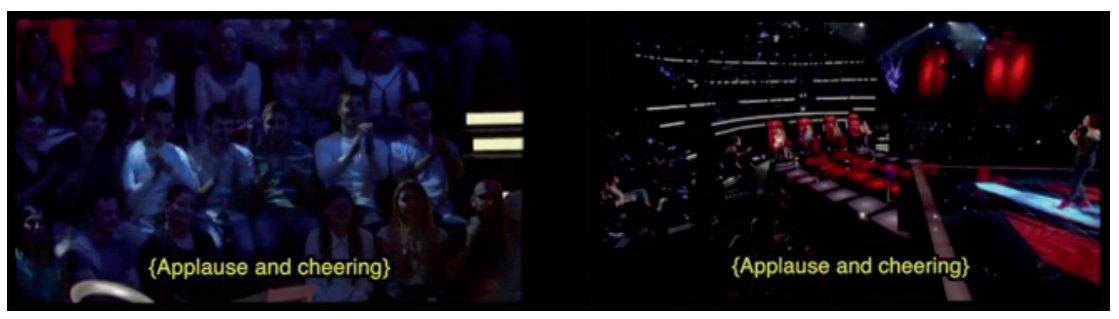

Figure 14: The audience.

In winning the support of the audience, the host dominates the rest of the conversation in this section. As the contestant attempts to justify her style of interaction in lines 50-51, the host interrupts her speech holding the floor and lectures her about the Turkish cultural norm that people prefer to use the formal you pronoun when they meet a person for the first time (lines 52-54, and 57-61). It is ironic, however, that in those lines the host himself uses nine instances of informal you pronoun to a person that he has just met. In response to the host's lecture, the contestant continues her attempts to explain her intention in lines 55$56,62-63,67$, and 69-70 but still using strong hand gestures and facial expressions (see Figure 13). The switch back to a medium-close-up shot during these moments clearly displays her continued assertiveness. During these moments, the host explains her "behavioral" misconduct further by visually depicting and imitating her style of interaction with the coaches (lines 64-66, and 71-72).

The host's remarks receive a new round of applause from the audience. Similar to the lines 45-49, we see a sequence of intercuts between the audience and the contestant in lines 74-76, and 95 to display the audience support for the host as the contestant grins in despair and does some facial expressions (see Figures 14 and 15). These shots again serve to reduce subjective alignment with the contestant.

Next, the host once again asks the contestant to compare herself with thousands other contestants and clarifies that her failing is not only the informal you pronoun she uses, but her general attitude and body language towards the coaches (lines 77-78, 80-81, and 84-90). In response, the contestant first tries to clarify

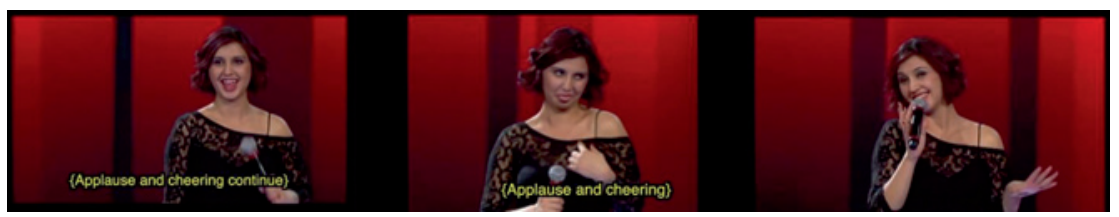

Figure 15: The contestant. 
how she understands the issue (line 91), but upon hearing the host's continued degrading comments (lines 92-93, and 96-97) and the audience's support for him (line 95), she returns to her assertive self and denies the host's allegations (lines 98-99).

What is striking in this line is that, as the contestant speaks, the camera intercuts to Coach $\mathrm{C}$ to display his displeasure and then shows a full shot of the contestant, which can be read as a distancing identification again (see Figure 16). Upon her denial of the problem, the host closes up the conversation by asking who wants to add her to his/her team in a rather ironic way. The camerawork at this moment shows various shots of the coaches, the contestant, and the audience. Especially those showing the coaches' displeased mood in contrast to the contestant's indifferent grinning face foreshadow the approaching trouble (see Figure 17).

The third section of the conversation begins when the contestant asks the two coaches who had turned their chairs (lines 103-104). Besides the awkward nature and timing of this question, her rather informal tone and word choice, namely "jaa, by the way," accompanied by hand gestures pointing at the coaches and the few steps she takes towards them as she speaks get immediate reaction from the audience (see Figure 18). Hearing the audience moan and groan, the contestant immediately retreats but cannot escape Coach C's direct reprimand repeating her question in a sarcastic way (line 107). At this very moment, the camera switches to a long establishing shot and zooms out, which can be read as another sign of

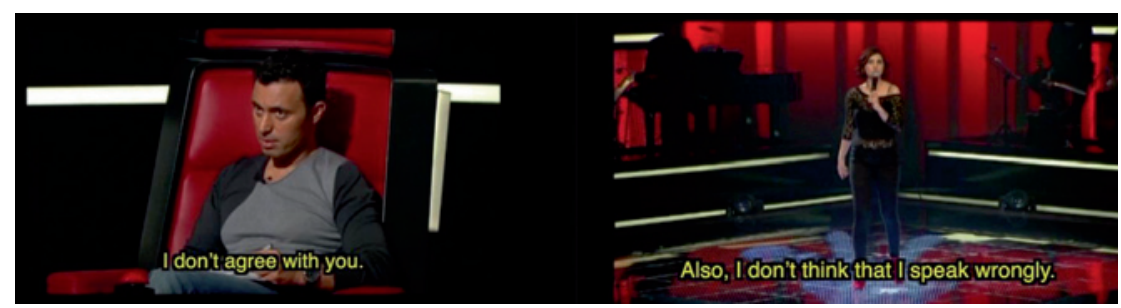

Figure 16: Distancing identification.

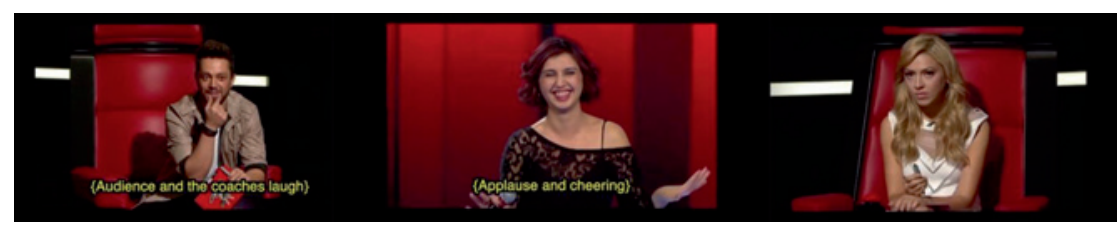

Figure 17: The coaches and the contestant. 


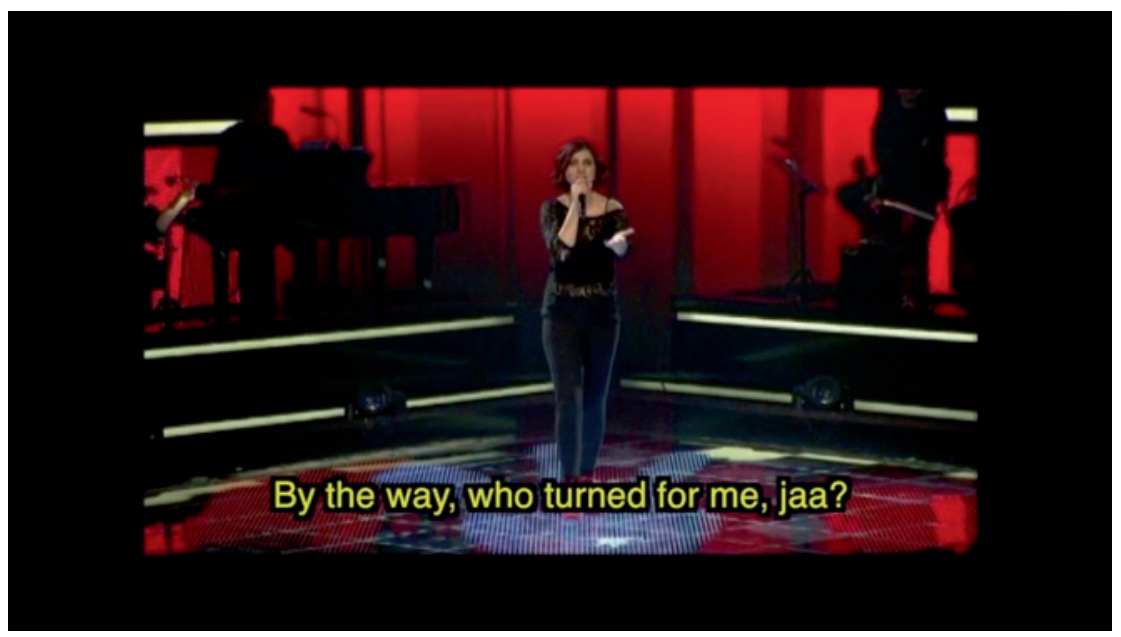

Figure 18: The contestant's continued informal manner.

distancing identification, thus reducing subjective alignment with her (see Figure 19). Then, the contestant is faced with Coach D's direct and blunt criticism (lines 108-109, and 111-112) and finally gets disqualified from the show and is sent off the stage by the host.

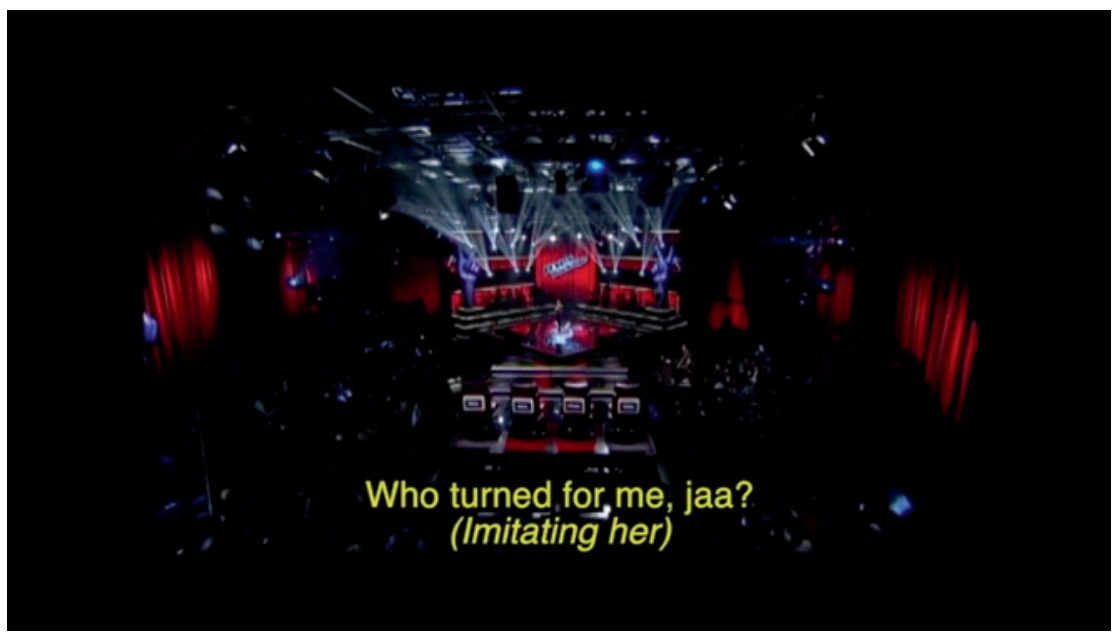

Figure 19: A long establishing shot. 
The coverage of the incident continues after the contestant leaves the stage. In the next scene, we see her meeting her aunt in the backstage. Trying to soothe her niece, the aunt says, "It is OK, my dear. No, no, no, it is OK. It is normal, OK, OK, OK. You will learn over time" (lines 122-123). What is striking in her words is that the aunt, as an elder to her, literally tells her that she should learn these norms over time, if not at home, at least through such experience. As a matter of fact, this contestant did learn her lesson in the end and appeared on the same stage in the following season of the show (see http://www.startv.com.tr/video-arsiv/nurcennet-ucar-ben-olmayinca). Her second performance attracted all four coaches, and all of them turned their chairs without knowing that it was her. This time, however, the contestant was extremely cautious about her words and style of speech.

\section{Discussion}

The moment-to-moment multimodal analysis of this incident in question reveals how various semiotic resources in the show - i. e., the audio-visual content and the stylistic elements - are mobilized to create and re-establish the media/non-media boundary which the contestant attempts to violate and undermine. The paradigmatic and syntagmatic orchestration of the dialog, audience responses, camerawork, and mise-en-scene throughout the sequence serve to construct a narrative in which the contestant's highly non-standard manners (interactionally, gesturally, and verbally) are marginalized and demonized while the host's advocacy of the social norms through policing the contestant's language and manners is glorified. Especially, the close-up shots of the contestant where she subverts the social expectations blatantly, and the subsequent close-up and establishing long-shots capturing the coaches' and the audience's reactions, respectively, are deployed to reflect and amplify the growing tension and opposition about the contestant. Yet, a critical question that begs an answer is why this opposition goes so far as to send the contestant off the stage. As I asked at the outset of the article, is it the violation of ethics or the violation of power structures that is so intolerable that it constructs a less than favorable image of the contestant and leads to her disqualification from the show without much objection?

The simple answer to this question is that it is both because ethics and power are inseparable components of social life. Derived from the Greek word "ethikos" meaning "habit” or "custom" (Lipari 2017), ethics refers to a society's acceptable practices and norms, in the emergence of which power plays an important role. Especially in interpersonal communication ethics, the power dynamics between interactants often sets the standards of right and wrong and determines the 
subjects and objects of ethical action and inquiry. In the case of The Voice or similar programs, in this regard, it is not surprising that "ordinary" participants are more likely to be subject to closer scrutiny in terms of codes of ethics because these are inherently asymmetrical situations where the celebrities as "experts" and the "hosts" hold a superior position. As a matter of fact, while the contestant in the particular incident is singled out for criticism and sent off the stage because of her style of speech and informal manners (despite her acquired right to join the competition), the coaches and the host are given a more accommodating and nonjudgmental space to interact with each other and the contestant. A striking example of this inequality occurs when the host uses nine instances of informal you pronoun to the contestant in a sentence in which he lectures about the cultural norm that people use the formal you pronoun when interacting with a person that they have just met (lines 52-54, and 57-61).

What is at stake here, however, is not that the celebrities have this privileged position and the vast majority of the viewers overlook the fact. On the contrary, it is rather that the majority inherently conform with this asymmetrical power structure and the ethics it entails. At least on the evidence of the edited sequence, the audience in the studio, even including the disqualified contestant's aunt at the end, find the host's intervention and decision unproblematic and even appropriate, which is presented and constructed both audio-visually and verbally throughout the sequence. It is this very conformity and the taken-for-granted enactment of power that constitute the essence of the media/non-media boundary in question. It is a boundary that is frequently crossed by many in today's postmodern world, but only insofar as they necessarily reproduce and legitimize the structures of power and social relations defined by it.

\section{Conclusion}

The analytical findings show how power in social settings governs human behavior, expectations, relationships, and undoubtedly how certain consequences follow if not adhered to. Especially in cases where asymmetrical power relations prevail, and individuals are particularly expected to represent what is supposedly known as the "standard etiquette," as in television programs like The Voice, the line between power and ethical behavior becomes even finer. In these communicative situations, complying with the existing structures of power and authority becomes taken-for-granted as the norm, and anything that exceeds them is easily relegated to the margins and demonized for not aligning with the best interest of the society. 
The incident analyzed in the article is a clear example of this phenomenon. It illustrates how a contestant's violation of the sanctity of elites is made into an ethical problem and narrated through a meticulously constructed video clip. In the analysis of this narrative and the power discourse that resides in it, the article adopts a multimodal approach and looks into both linguistic and other audiovisual (semiotic) resources available in the video, such as the camerawork and mise-en-scene, because it is the whole composition of these communicative artifacts and the interplay among them that make up a televisual narrative. The findings broaden our understanding of how discourses are constructed in social relations, particularly on television programs, and emphasize the importance of multimodal approaches in discourse studies as a step forward from a traditional sociolinguistic-oriented critical discourse analysis.

\section{References}

Adriaens, Fien \& Daniel Biltereyst. 2012. Glocalized telenovelas and national identities: A "textual cum production" analysis of the "telenovelle" Sara, the Flemish adaptation of Yo soy Betty, la fea. Television \& New Media 13(6). 551-567. https://doi.org/10.1177/ 1527476411427926.

Aveyard, Karina, Pia M. Jensen \& Albert Moran. 2016. New patterns in global television formats. Bristol, UK: Intellect.

Bateman, John A. \& Karl-Heinrich Schmidt. 2012. Multimodal film analysis: How films mean. New York: Routledge.

Bateman, John A., Janina Wildfeuer \& Tuomo Hiippala. 2017. Multimodality: Foundations, research, and analysis: A problem-oriented introduction. Berlin: De Gruyter Mouton.

Baudrillard, Jean. 2011. The precession of simulacra. In Meenakshi G. Durham \& Douglas M. Kellner (eds.), Media and cultural studies: Keyworks, 2nd edn, 453-481. Malden, MA: WileyBlackwell.

Bielby, Denise D. \& C. Lee Harrington. 2008. Global TV: Exporting television and culture in the world market. New York: New York University Press.

Chalaby, Jean K. The format age: Television's entertainment revolution. Malden, MA: Polity Press.

Couldry, Nick. 2001. The hidden injuries of media power. Journal of Consumer Culture 1(2). 155-177. https://doi.org/10.1177/146954050100100203.

Dash, Amarendra K. \& Priyadarshi Patnaik. 2016. A multimodal discourse analysis of glocalization and cultural identity in three Indian TV commercials. Discourse \& Communication 10(3). 209-234. https://doi.org/10.1177/1750481315623892.

Dechert, Andre. 2016. A case of asynchronous media change in the 1950s: How US-American TV series came to early West German television. Global Media Journal 6(2). 1-14. https://urn. nb.no/URN:nbn:de:gbv:547-201600620.

Eriksson, Göran. 2016. Humour, ridicule and the de-legitimization of the working class in Swedish reality television. Journal of Language and Politics 15(3). 304-321. https://doi.org/10.1075/ jlp.15.3.05eri. 
Eriksson, Göran \& David Machin. 2017. The role of music in ridiculing the working classes in reality television. In Lyndon C. S. Way \& Simon McKerrell (eds.), Music as multimodal discourse: Semiotics, power and protest, 21-46. London \& New York: Bloomsbury Academic.

Ferrari, Chiara. 2012. "National Mike": Global host and global formats in early Italian television. In Tasha Oren \& Sharon Shahaf (eds.), Global television formats: Understanding television across borders, 128-147. New York: Routledge.

Fiske, John. 2011. Television culture, 2nd edn. London: Routledge.

Ganguly, Lauhona. 2012. Global television formats and the political economy of cultural adaptation: Who wants to be a millionaire? in India. In Tasha Oren \& Sharon Shahaf (eds.), Global television formats: Understanding television across borders, 323-345. New York: Routledge.

Gray, Jonathan \& Amanda D. Lotz. 2019. Television studies, 2nd edn. Malden, MA: Polity Press. Havens, Timothy. 2006. Global television marketplace. London: British Film Institute.

Holt, Jennifer \& Kevin Sanson (eds.). 2014. Connected viewing: Selling, streaming, \& sharing media in the digital era. New York: Routledge.

Jewitt, Carey (ed.). 2014. The Routledge handbook of multimodal analysis. New York: Routledge. Kress, Gunther. 2003. Literacy in the new media age. London: Routledge.

Larkey, Edward, Landry Digeon \& Ibrahim Er. 2016. Measuring transnationalism: Comparing TV formats using digital tools. VIEW Journal of European Television History and Culture 5(9). 72-92. https://doi.org/10.18146/2213-0969.2016.jethc104.

Ledin, Per \& David Machin. 2017. Multi-modal critical discourse analysis. In John Flowerdew \& John E. Richardson (eds.), The Routledge handbook of critical discourse studies, 60-76. London: Routledge.

Lipari, Lisbeth A. 2017. Communication ethics: Oxford Research Encyclopedia of Communication. https://oxfordre.com/communication/view/10.1093/acrefore/9780190228613.001.0001/ acrefore-9780190228613-e-58 (accessed 27 February 2019).

Littler, Jo. 2004. Making fame ordinary: Intimacy, reflexivity and 'keeping it real.'. In Jonathan Rutherford (ed.), Mediactive, 8-25. London: Lawrence \& Wishart.

Machin, David. 2013. What is multimodal critical discourse studies? Critical Discourse Studies 10(4). 347-355. https://doi.org/10.1080/17405904.2013.813770.

Machin, David \& Andrea Mayr. 2012. How to do critical discourse analysis. London: Sage Publications.

Miller, Toby \& Marwan M. Kraidy. 2016. Global media studies. Malden, MA: Polity Press.

Moran, Albert. 2009. New flows in global TV. Bristol, UK: Intellect.

O’Halloran, Kay L., Kwan Lin E. Marissa, Alexey Podlasov \& Sabine Tan. 2013. Multimodal digital semiotics: The interaction of language with other resources. Text \& Talk 33(4-5). 665-690. https://doi.org/10.1515/text-2013-0030.

Oren, Tasha and Sharon Shahaf (eds.). 2012. Global television formats: Understanding television across borders. New York: Routledge.

Parks, Lisa \& Shanti Kumar (eds.). 2003. Planet TV: A global television reader. New York: New York University Press.

Unur, Ayşegül K. 2015. Discussing transnational format adaptation in Turkey: A study on Kuzey Güney. SERIES International Journal of TV Serial Narratives 1(2). 139-150. https://doi.org/10. 6092/issn.2421-454X/5899.

van Keulen, Jolien \& Tonny Krijnen. 2014. The limitations of localization: A cross-cultural comparative study of Farmer Wants a Wife. International Journal of Cultural Studies 17(3). 277-292. https://doi.org/10.1177/1367877913496201. 
Yeşil, Bilge. 2015. Transnationalization of Turkish dramas: Exploring the convergence of local and global market imperatives. Global Media and Communication 11(1). 43-60. https://doi.org/ 10.1177/1742766515573274.

Yeşil, Bilge. 2016. Media in new Turkey: The origins of an authoritarian neoliberal state. Urbana, Chicago, and Springfield: University of Illinois Press.

\section{Bionote}

Ibrahim Er earned his Ph.D. in the interdisciplinary program of Language, Literacy, and Culture at the University of Maryland, Baltimore County in 2020. His research interests encompass media, culture, and globalization, with a specialization in Turkish television, politics, and culture. His research focuses on the global flow of transnational television formats and their reproduction and reimagining in different national settings as they work their way through different political landscapes and media cultures. Address for correspondence: Language, Literacy, and Culture Doctoral Program, University of Maryland, Baltimore County, 1000 Hilltop Circle, Baltimore, MD 21250, USA. Email: ibrahimer@umbc.edu 